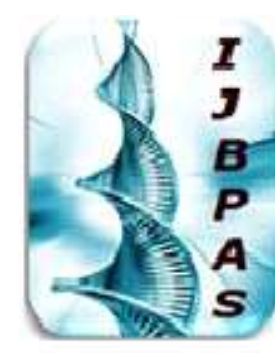

International Journal of Hiology, Pharmacy and Allied Seiences (IJBPAS) 'A Bridge Betuen Caboratory and Qnendo'

Www.ijbpas.com

METHOD DEVELOPMENT AND VALIDATION OF TENELIGLIPTIN BY RP-HPLC METHOD

\title{
PULATE $C^{*}$, TARE H AND DAMA G
}

Shri Gajanan Maharaj Shikshan Prasarak Mandal's Sharadchandra Pawar College of Pharmacy, Dumbarwadi (Otur), Tal. Junnar, Dist. Pune, M.S., India

*Corresponding Author: Chetan Pulate: E Mail: harshaltare51@gmail.com Received $19^{\text {th }}$ April 2021; Revised $20^{\text {th }}$ June 2021; Accepted $29^{\text {th }}$ July 2021; Available online $1^{\text {st }}$ Oct. 2021 https://doi.org/10.31032/IJBPAS/2021/10.10.1010

ABSTRACT

A sensitive, exact, rapid and robust HPLC method was developed for the quantification of Teneligliptin (TG) with UV detector. In this method, a reversed-phase Grace C18 $(250 \mathrm{~mm} x$ 4.6ID, Particle size: 5 micron) column with a mobile phase of methanol: $0.05 \%$ OPA (20:80; $\mathrm{v} / \mathrm{v}$ ) at $0.8 \mathrm{ml} / \mathrm{min}$ flow rate was used to separate TG with a detection of $249 \mathrm{~nm}$. The volume injected was $20 \mu \mathrm{L}$. The retention time of TG was obtained as $5.255 \mathrm{~min}$. All necessary validation parameters and system suitability tests were carried out in details. The analytical curve was linear $\left(r^{2}=0.999\right)$ over a wide concentration range $(10-50 \mu \mathrm{g} / \mathrm{ml})$. The system shows adequate accuracy with relative standard deviation less than $2.0 \%$. The method showed good duplicability and recovery with $\%$ RSD less than $2 \%$. So, the proposed system was found to be simple, specific, precise, accuracy, linear, and rugged. Hence it can be applied for practice analysis of Teneligliptin (TG) in bulk drug.

Keywords: RP-HPLC estimation, Method development, Validation, Teneligliptin INTRODUCTION

Analytical chemistry termed as science of determining the components of materials in terms of the elements or compound contained. The approach of this science is used to recognize the substances which may be present in a material and to determine the 
exact amounts of the identified substances. Analytical chemistry is important in nearly all aspects of chemistry. Analytical techniques proved in assuring and maintaining the quality of substance and are critical components of QA and QC [1, 2].

Analytical method should be,

1. Most productive, economical and convenient,

2. As accurate and precise as required,

3. As simple as possible,

4. Most specific

Should be fully optimized before transfer for validation of its characteristics such as precision, accuracy, sensitivity etc.

A new class of anti-diabetic drugs, Dipeptidyl peptidase-4 (DPP-4) inhibitors have recently introduced, that show enthusiastic results in the treatment of glycemic control with a minimal risk of hypoglycemia and weight gain. Teneligliptin, a novel Dipeptidyl peptidase-4 inhibitor, has a unique structure characterized by five consecutive rings, which produce a potent and long-lasting effect. Teneligliptin is now used as treatment in cases of insufficient improvement in glycemic control even after diet control and exercise and also a combination of diet control, exercise, and sulfonylurea- or thiazolidine-class drugs [3, 4].
Teneligliptinis 1-(3-methyl-1-phenyl-1Hpyrazol-5-yl)-4-[(3S,5S)-5-(1,3-thiazolidine3 carbonyl)pyrrolidin-3- yl]piperazine $(\mathrm{C} 22 \mathrm{H} 30 \mathrm{~N} 6 \mathrm{OS})$ and its structure is shown in Figure 1.

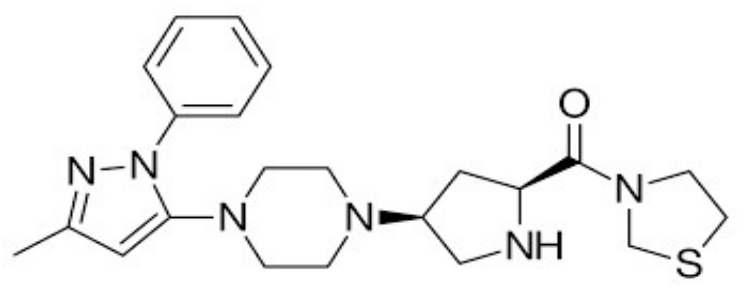

Figure 1: Chemical structure of Teneligliptin

\section{MATERIAL AND METHODS}

Reagents and Chemicals: Water, Orthophosphoric acid, Methanol were used in the study.

\section{Chromatographic condition:}

A High performance liquid chromatogram equipped with UV-VIS detector, the purity determination performed on a Grace C18 (250mm x 4.6ID, Particle size: 5 micron) long filled. C18 column the mobile phase consisting of Methanol: 0.05\%OPA (20:80) [5].

\section{Preparation of Teneligliptin Standard:}

Weighed accurately about 10mg of Teneligliptin standard and transffered into $10 \mathrm{~mL}$ of volumetric flask, added about $5 \mathrm{~mL}$ of diluent, shaked to dissolved and volume was made up to the mark with diluent. (concentration of Teneligliptin $1000 \mu \mathrm{g} / \mathrm{ml}$ ). Further diluted $0.2 \mathrm{~mL}$ of above stock solution to $10 \mathrm{~mL}$ of volumetric flask and 
volume was made up to the mark with diluent (concentration of Teneligliptin 20 $\mu \mathrm{g} / \mathrm{ml})[6]$.

Preparation of stock solution of Teneligliptin:

Twenty tablets were weighed and finely powdered. An accurately weighed amount of powder equivalent to $20 \mathrm{mg}$ of $\mathrm{TG}$ was transferred into a $10.0 \mathrm{ml}$ volumetric flask. Then $5.0 \mathrm{ml}$ of diluent was added in it. The flask contents were sonicated for $10 \mathrm{~min}$ to make the contents homogeneous. This solution was then diluted up to the mark with diluent. The resultant solution was filtered through Whatman Grade I filter paper. One milliliter of the filtrate was transferred to a $10 \mathrm{ml}$ volumetric flask and then the volume was made up to the mark with diluent to furnish a sample solution containing 40 $\mu \mathrm{g} / \mathrm{ml}$ of TG [7].

Method evolution: Analytic system development and prove are answer component of any pharmaceutical growth program. HPLC examination method is developed to recognize, amount or purifying combination of attentiveness. This practical short will centre on development and validation activities as put in to drug result. successful method evolution make sure that lab resources are optimized, while methods meet the objectives required at each stage of drug development. procedure validation, required by regulate agencies at certain phase of the drug acceptance process, is explain as the process of reveal Teneligliptin that analytical procedures are acceptable for their intended use [8].

\section{Validation parameter: [9]}

The objective of validation of an analytical procedure is to demonstrate that it is suitable for its intended purpose. A tabular summation of the characteristics applicable to the identification, control of impurities and assay procedures is included. Other logical course of action may be considered in later additions to this document. Definative validation attribute, which should be considered, are listed below

- Linearity.

- Accuracy.

- Precision.

- Limit of Detection (LOD).

- Limit of Quantification (LOQ).

- System suitability parameter.

Linearity: Linearity is the ability of the analytical procedure to obtain a response that is directly proportional to the concentration (amount) of analyte in the sample. If the method is linear, the test results are directly or by well-defined mathematical Teneligliptin transformation proportional to the concentration Teneligliptin of an analyte 
in samples within a given span at which the involved response is proportional to the analyte concentration.

Accuracy: Accuracy is the nearness of a measured value to the true or accepted value. Accuracy designate the digression between the convey merit found and the true merit. It is determined by applying the method to samples to which known amounts of analyte have been added. These should be analyzed against the standard and blank solutions to ensure that no interference exists.

Precision: The exactness of a logic method is the level of accord among single test results get when the method is pragmatic to many sampling of a similar sample. Precision is a measure of the dependability of the whole analytical process.

\section{Limit of Detection (LOD)}

The detection limit of an individual analyte procedure is the lowest amount of analyte which can be detected not necessarily quantified as an exact value. LOD was calculated using the following formula.

\section{LOD $=3.3 \sigma / S$}

Where $\sigma$ is the standard deviation calculated from accuracy of the response and $\mathrm{S}$ is the slope from linearity

\section{Limit of Quantification (LOQ)}

The quantification limit of an individual analytical procedure is the lowest amount of analyte which can be quantitatively determined. LOQ was calculated using the following formula.

\section{$\mathrm{LOQ}=\mathbf{1 0 . \sigma} / \mathrm{S}$}

Where $\sigma$ is the standard deviation calculated from accuracy of the response and $\mathrm{S}$ is the slope from linearity.

\section{System suitability parameter:}

System suitability parameter is the evaluation of a composition of an analytical system to show that the performance of the system meets the standard required by the method. This parameter can be calculated experimentally to provide a quantities system suitability test report number of theoretical plates (efficacy ) capacity factor, separation (relative retention), resolution, telling factor relative standard deviation (precision).

\section{RESULTS AND DISCUSSION}

\section{Determination of $\lambda$ max}

Initially the Ultra violet (U.V) spectrum of Teneligliptin was produced using appropriate U.V spectrophotometer, so as to determine the absorbance maxima or Lambda max $(\lambda$ max). This is essential since HPLC detection is basically UV based, thus a $20 \mu \mathrm{g} / \mathrm{ml}$ solution of Teneligliptin in water was used to get the following spectra (Figure 2).

Linearity: For calculating linearity of Teneligliptin a series of standard preparation of Teneligliptin was prepared over a range of 
10 to $50 \mu \mathrm{g} / \mathrm{ml}$ of working concentration level. The response of the drug was found to be linear in the investigation concentration range and the linear regression equation for Teneligliptin was $\mathrm{Y}=106.0 \mathrm{x}-29.58$ with correlation coefficient 0.999 (Figure 3).

\section{Accuracy:}

Recovery of Teneligliptin was determined at three different concentration levels (Table 3). The result indicating that the method was accurate.

\section{Precision:}

The \% RSD of intraday precision and interday precision were 0.23 and 0.24 for
TG. The percentage RSD of system, method, and intermediate precision study was well within the limits $(<2 \%)$, indicate that the method was precise. The results of precision are shown in Table 4.

\section{System suitability parameters:}

The standard solution was prepared by earlier mentioned procedure. After equilibration of column with mobile phase, six replicate injections of $20 \mu \mathrm{L}$ solution were injected. The chromatograms were recorded and peak response i.e. peak area was measured [10]. The results of system suitability parameters are shown in Table 4.

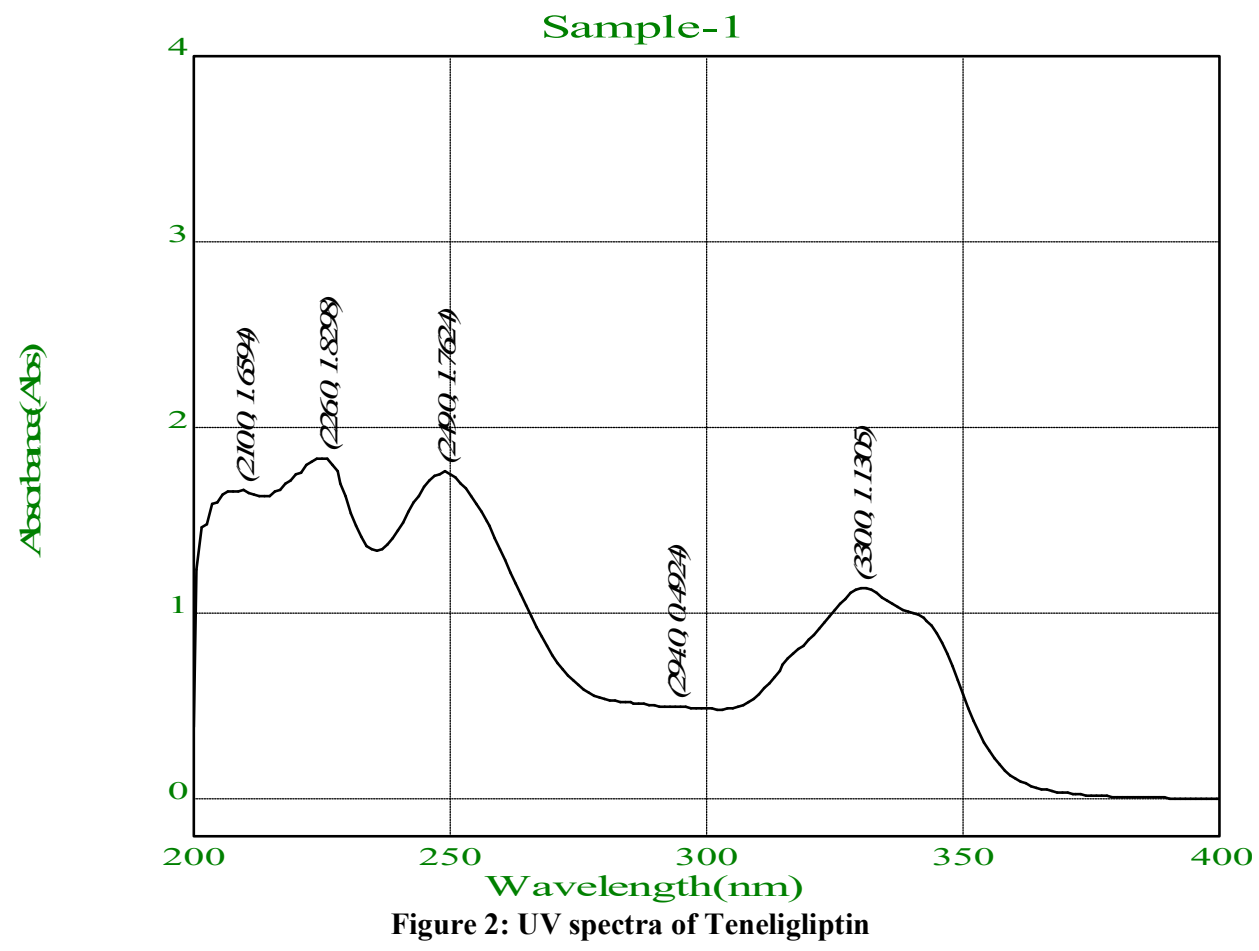

IJBPAS, Octo6er, Special Issue, 2021, 10(10) 
Table 1: Chromatographic condition for Teneligliptin drug validation

\begin{tabular}{|c|c|}
\hline PARAMETER & CONDITIONS \\
\hline Stationary Phase (Column) & $\begin{array}{c}\text { Grace C18 (250mm x 4.6ID, Particle size: } 5 \\
\text { micron) }\end{array}$ \\
\hline Mobile Phase & Methanol: 0.05\%OPA (20:80) \\
\hline Flow rate & $\mathbf{0 . 8 m l} / \mathbf{m i n}$ \\
\hline Injection volume & $20 \mu \mathrm{L}$ \\
\hline Pump mode & Isocratic \\
\hline Detector & UV VIS \\
\hline Wavelength & $249 \mathrm{~nm}$ \\
\hline Column Temperature & $25^{\circ} \mathrm{C}$ \\
\hline Run Time & $10 \mathrm{~min}$ \\
\hline Retention Time & 5.255 \\
\hline
\end{tabular}

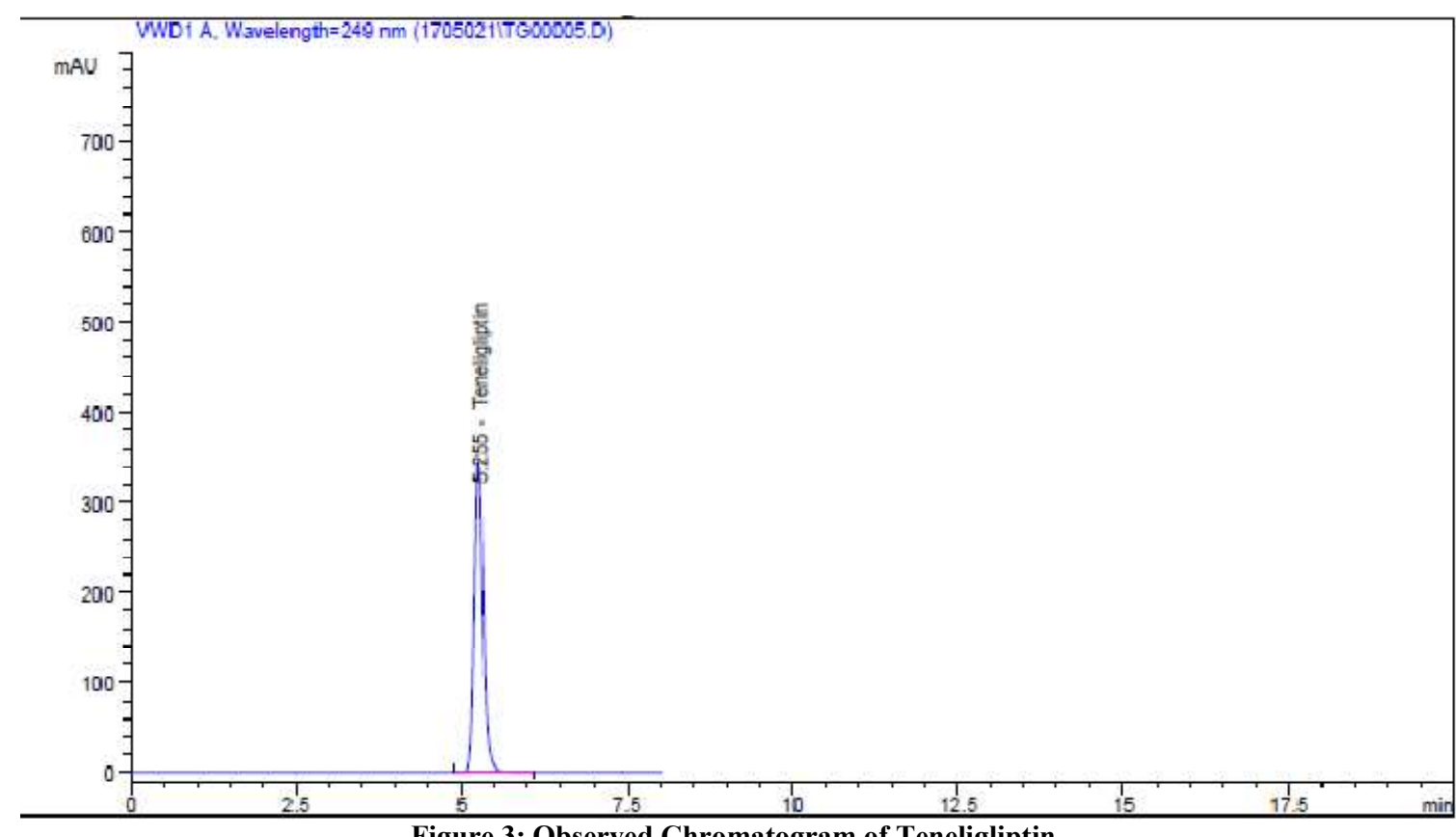

Figure 3: Observed Chromatogram of Teneligliptin

Table 2: Linearity of Teneligliptin

\begin{tabular}{|c|c|c|c|}
\hline $\begin{array}{c}\text { \% Conc. of } \\
\text { Standard }\end{array}$ & $\begin{array}{c}\text { Mean Response } \\
\text { (Area) }\end{array}$ & \multicolumn{2}{|c|}{ Statistical analysis } \\
\cline { 1 - 2 } 10 & 1040.2 & \multirow{2}{*}{ Correlation } & 0.999 \\
\hline 20 & 2053.35 & & 29.58 \\
\hline 30 & 3217.53 & Intercept & 106.0 \\
\hline 40 & 4163.78 & Slope & \\
\hline 50 & 5288.88 & &
\end{tabular}




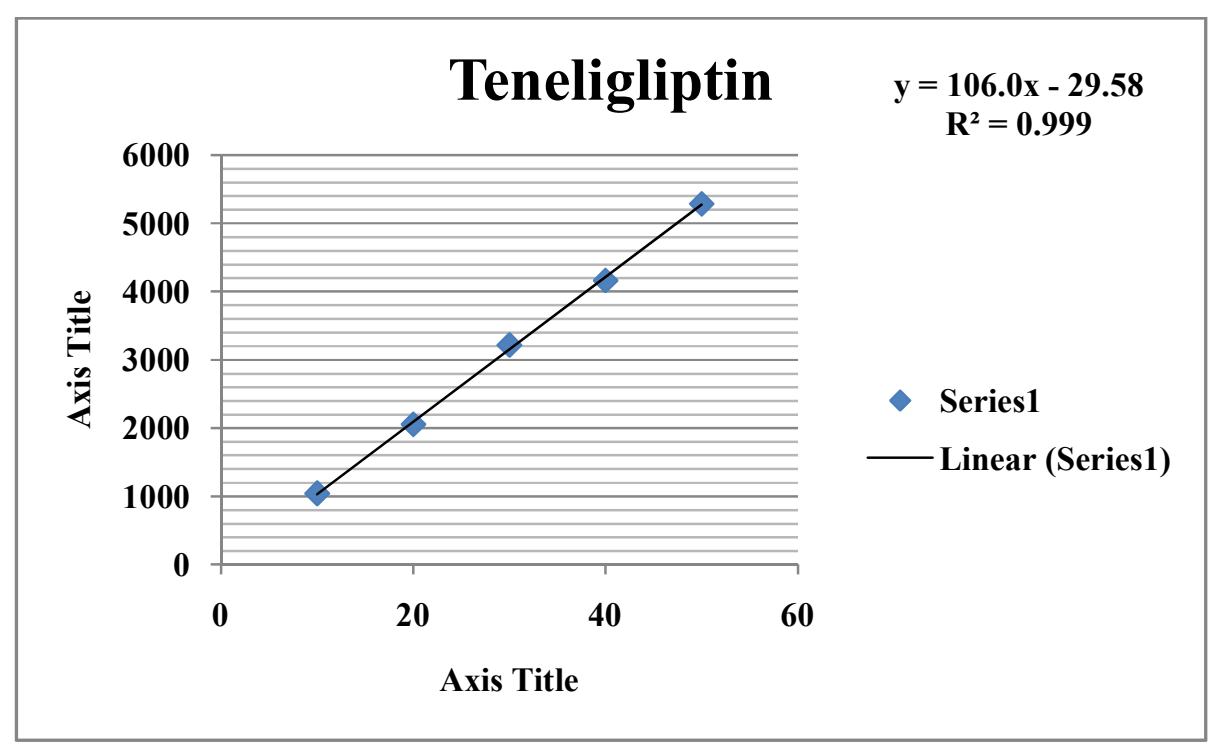

Figure 4: Linearity graph of Teneligliptin

Table 3: Accuracy data sheet

\begin{tabular}{|c|c|c|c|c|}
\hline Drug & Level & Amount taken & Amount Found & \% Recovery \\
\hline \multirow{3}{*}{ TG } & $\mathbf{8 0}$ & 8 & 17.98 & 99.85 \\
\cline { 2 - 5 } & 100 & 10 & 20.26 & 102.64 \\
\cline { 2 - 5 } & 120 & 12 & 22.17 & 101.40 \\
\hline
\end{tabular}

Table 4: Summary of validation parameter

\begin{tabular}{|c|c|}
\hline Parameter & TG \\
\hline Calibration Range $(\mu \mathrm{g} / \mathrm{ml})$ & $10-50$ \\
\hline Optimized wavelength $(\mathrm{nm})$ & $\mathbf{2 4 9} \mathrm{nm}$ \\
\hline Retention Time & 5.255 \\
\hline Precision $(\%$ RSD) & $\mathbf{0 . 2 3 - 0 . 2 4}$ \\
\hline System suitability $(\%$ RSD) & 1.28 \\
\hline \% Assay & 99.49 \\
\hline LOD $(\mu \mathrm{g} / \mathrm{ml})$ & $\mathbf{0 . 6 1 6}$ \\
\hline LOQ $(\mu \mathrm{g} / \mathrm{ml})$ & 1.866 \\
\hline
\end{tabular}

Average of five determinations, LOD: Limit of detection, LOQ: Limit of quantification

\section{CONCLUSION}

It can be concluded from the entire work that HPLC is a versatile, reproducible chromatographic technique for the estimation of drug products. It has broad request in different pasture in word of quantitative and qualitative approximation of energetic particle. Final optimization can be performed by changing the temperature, gradient slope, and flow rate as well as the type and conc. of mobile-phase modifiers. The optimized method is validated with various parameters (e.g. accuracy, precision, linearity, detection limit etc.) as per ICH guidelines. The use of the $\mathrm{C} 18$ column in the present work has shown better elution of analytes with good resolution, improved plate count, capacity factor. So the C18 column can be used to achieve high specificity in the shorter time of analysis of Teneligliptin as per ICH Q2 (R2) 
guidelines. The proposed method was found to be simple, precise, accurate, linear, robust and rapid determination and quantification of Teneligliptin. This developed and validated the method for analysis of Teneligliptin in pharmaceutical preparations is very rapid, accurate, and precise. Moreover, it has advantages of short runtime and the possibility of analysis of a large number of samples, both of which significantly reduce the analysis time per sample.

\section{REFERENCES}

[1] Singh R. HPLC method development and validation-an overview. Journal of Pharmaceutical Education \& Research. 2013 Jun $1 ; 4(1)$.

[2] Guideline IH. Validation of analytical procedures: text and methodology. Q2 (R1). 2005 Nov; 1(20): 05.

[3] Bhardwaj SK, Dwivedia K, Agarwala DD. A review: HPLC method development and validation. International Journal of Analytical and Bioanalytical Chemistry. 2015; 5(4): 7681.

[4] Gupta V, Jain AD, Gill NS, Guptan K. Development and validation of HPLC method-a review. International research journal of pharmaceutical and applied sciences. 2012 Aug 31; 2(4): 17-25.

[5] Davidson, A. G., Beckett, A. H., \& Stenlake, J. B. Practical Pharmaceutical Chemistry, 1997.
[6] Zinjad SS, Patel SG, Gaikwad DD, Jadhav SL. Analytical Method Development of Saxagliptin $\mathrm{HCl}$ by RP-HPLC. Journal of Drug Delivery and Therapeutics. 2019 Jul 15; 9(4): 274-8.

[7] ICH I. Q2 (R1): Validation of analytical procedures: text and methodology. InInternational Conference on Harmonization, Geneva 2005 Nov.

[8] Lokhande P. Analytical Method Development and Validation of Teneligliptin by using RP-HPLC with ICH Guidelines. 2019.

[9] Kumar TG, Vidyadhara S, Narkhede NA, Silpa YS, Lakshmi MR. Method development, validation, and stability studies of teneligliptin by RP-HPLC and identification of degradation products by UPLC tandem mass spectroscopy. Journal of Analytical Science and Technology. 2016 Dec; 7(1): 1-2.

[10]Bichala PK, Kumar KJ, Suthakaran R, Shankar C. Development and Validation of an Analytical Method for the Estimation of Metformin and Teneligliptin in its Bulk and Tablet Dosage Form by using RP-HPLC. Asian Journal of Pharmaceutical Analysis. 2020; 10(1): 11-4. 